\title{
Multidisciplinary forensic investigation into a partially burnt dismembered body found by a road side
}

Edirisinghe PAS*, Kitulwatte IDG, Gangahawatta S

Department of Forensic Medicine, Faculty of Medicine, University of Kelaniya

*Corresponding author: Tel - 0094-71-8426420, e mail: anuruddhi@hotmail.com

MLJSL.Vol 2. No 2. September. pp 45-49

\begin{abstract}
Introduction

Forensic investigation into dismembered remains needs involvement of a multidisciplinary forensic team. In such situations, actions taken at the crime scene investigation play an important role. Often these crime scenes involve multiple locations. We report the forensic investigation of a partially burnt dismembered body found on a roadside to highlight the need of a multidisciplinary approach.
\end{abstract}

\section{Case report}

Decapitated, partially burnt human remains disremembered into seven parts were recovered from a road side in a residential area. The primary challenge was identification of the deceased. A systematic multidisciplinary scene visit conducted by crime scene officers, forensic pathologists and arson specialist revealed the primary scene of crime was different from the burnt site. Partly burnt "Friendship wrist bands" found in the right upper limb linked the body to a missing young man. Personal information of the missing person's general identity was compatible with autopsy findings. Further investigations of the missing person's last movements led to the original crime scene in a room in the $4^{\text {th }}$ floor of a building. Although the primary site had been "washed away", remnants of the blood stains were sufficient to reconstruct the events. DNA investigations confirmed the identification of the 'missing person'.

\section{Conclusion:}

Dismemberment and burning are linked with multiple "crime sites" and concealing of identity and the cause of death. Establishment of the identity most of the time helps to reconstruct the event through other corroborative evidence.

Key words: forensic investigation, dismembered, burnt, remains, identification, event reconstruction

\section{Introduction}

Dismemberment and burning is an attempt to conceal the identity and thereby the crime. However, the assumption of the investigators in such situation is that the manner of death is homicide though it may not invariably true [1].Forensic investigation into dismembered remains needs the involvement of a multidisciplinary forensic team [2, 3].Careful, 
thorough investigation is the key to ensure proper administration of justice. In such situations, actions taken at the crime scene investigation play an important role. Often these crime scenes involve multiple locations. We report the forensic investigation of a partially burnt dismembered body found on a roadside to highlight the multidisciplinary approach to bring justice to the victim.

\section{Case report}

Decapitated, partially burnt human remains dismembered into seven parts were recovered from a road side in a residential area (Photograph: 1).

Photograph 1: Scene visit partly burnt body parts and wilted burnt leaves indicatingthe flames of the fire/ heat of the fire have reached a considerable height (15 feet)

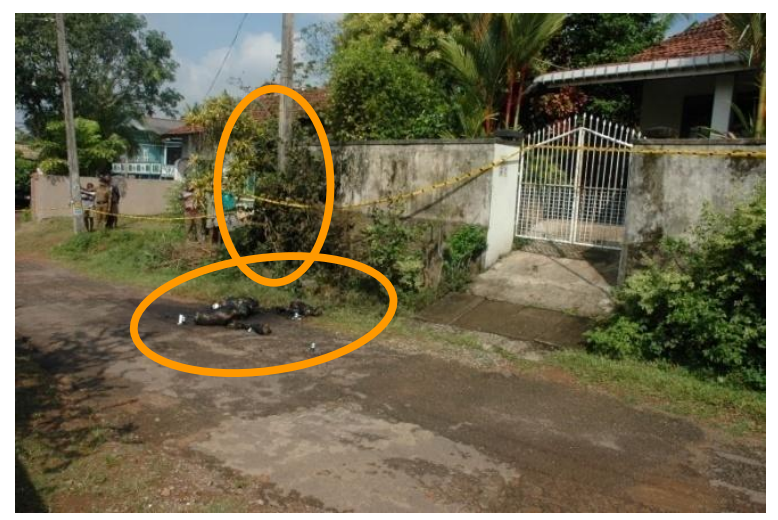

Partly burnt "Friendship wrist bands" found in the right upper limb linked to a missing young man. (Photograph 2 \& 3)

Missing person's data and post-mortem data were obtained using Interpol Disaster Victim identification forms. Although general identification was possible using matching data specific identification was impossible using conventional methods such as finger prints and dental pattern due to burning and absence of a dental chart during life.

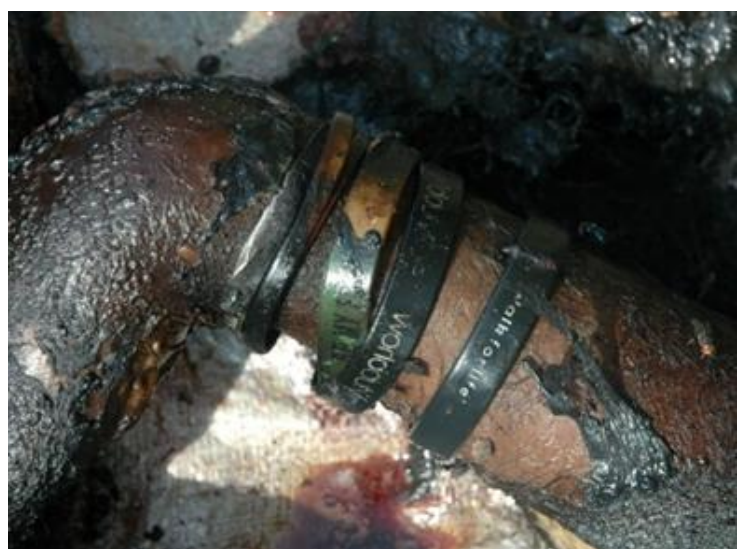

Photograph 02: friendship bands

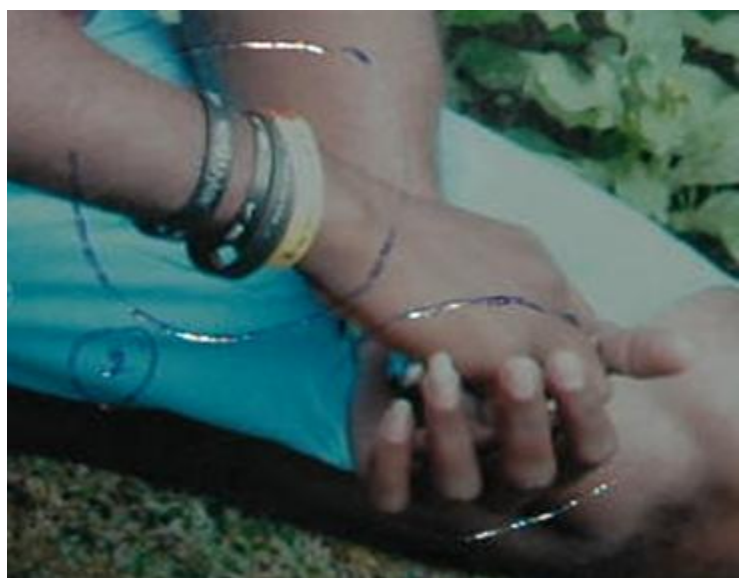

Photograph 03: friendship bands in the missing person

Soot was not found in the respiratory tract. Test for carbon monoxide reported negative. There were no identifiable ante-mortem injuries of either blunt or sharp force trauma to arrive at a cause of death. The dismembered bony ends showed sharp cuts at several sites, cervical spine, lumbar spine, femurs and humerus. (photographs 4-9) Radiological investigations did not reveal presence of bullets or pellets emitted from a firearm. Stomach contents reported negative for common poisons. Further investigations of the missing person's last movements led to the original crime scene at a room in the $4^{\text {th }}$ floor of a building.

Although the primary site had been "washed away" remnants of the blood stains were enough to reconstruct the events. 


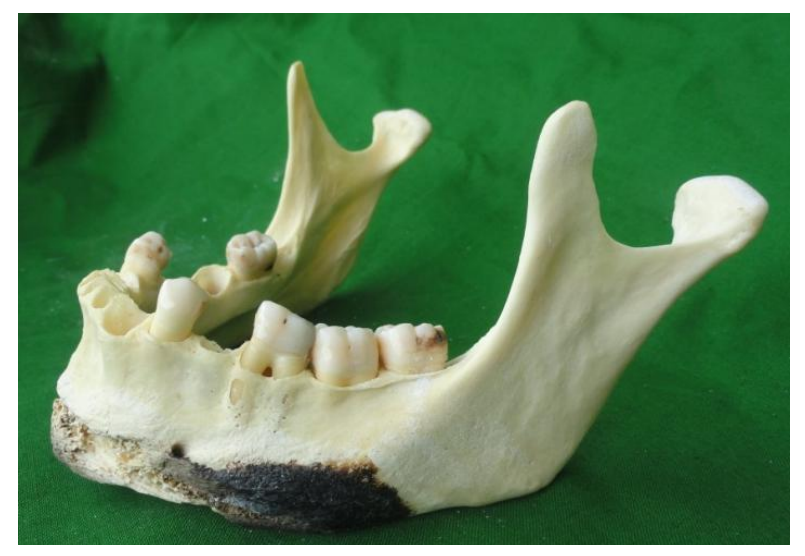

Photograph 04 : burn and cut fracture of mandible

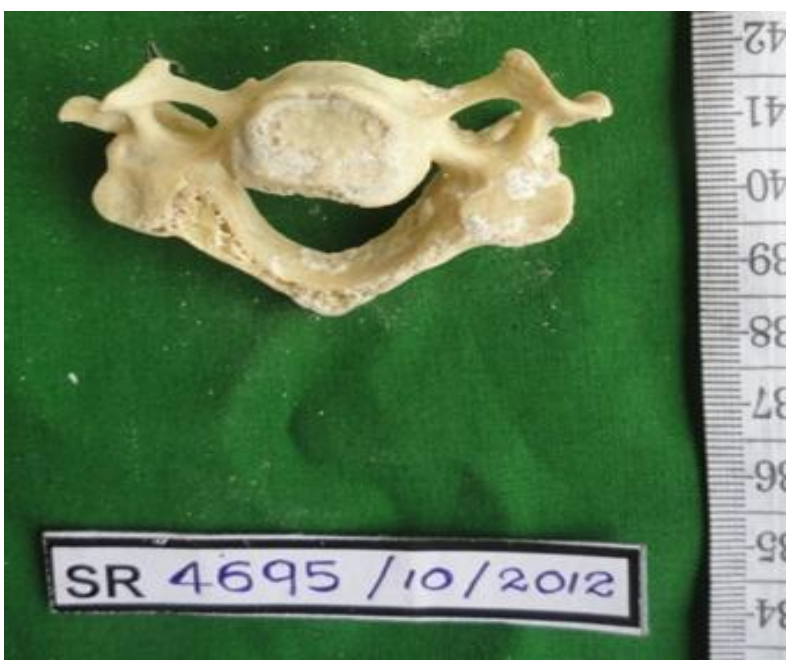

Photograph 05: cut fracture of the $4^{\text {th }}$ cervical vertebra



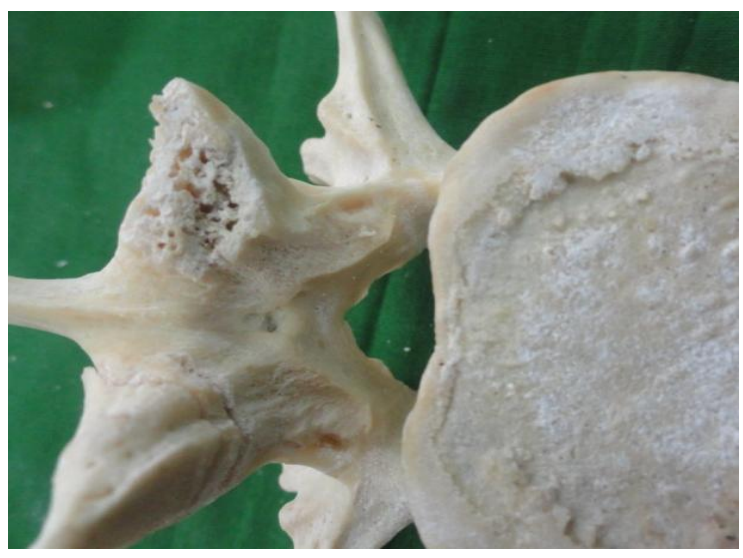

Photograph 06 \&07 : Partial and total cut injury of the right and left superior articular processes of $4^{\text {th }}$ Lumbar vertebra
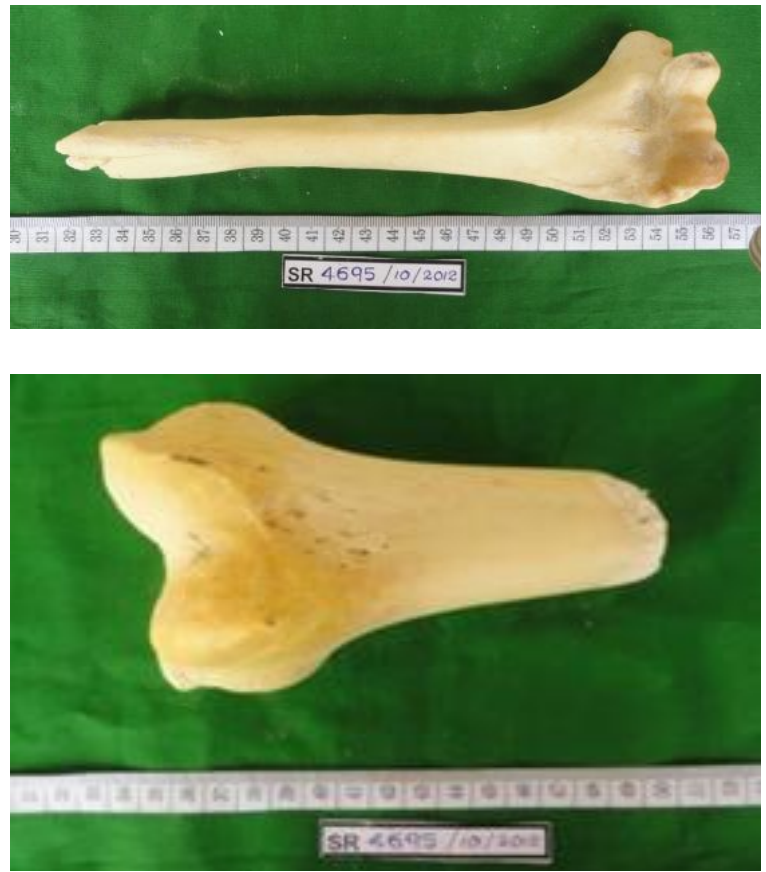

Photograph 08 \& 09: cut ends of humerus and femur

DNA investigations done by comparing the DNA obtained from the bone marrow of this victim with that of his mother and sister confirmed the identification of the 'missing person'. 


\section{Discussion}

Dismemberment and burning are a form of elaborate planned concealment of a body and are associated with homicide [4]. The motive of the post mortem dismemberment is not only to conceal the identity and the crime, but also to facilitate the disposal. It is often linked with multiple "crime sites". The body is located in the primary crime scene. Other crime scenes may include: the place of the initial physical attack, the place of death and the vehicle used to move the body. There may be traces of the murderer and the victim at each scene. Involvement of a multidisciplinary team is crucial in proper forensic investigation of such crime. A systematic multidisciplinary scene visit conducted by crime scene officers, forensic pathologists and arson specialist revealed that the primary scene of crime is different from the burnt site. Establishment of the identity of a mutilated corpse most of the time helps to reconstruct the event through other corroborative evidence.

The primary challenge faced by the investigators in this case was the identification of the deceased. Circumstantial and historical evidence obtained by the police Scene of Crime Officers (SOCO) revealed that there was a missing young man from the area. Partly burnt friendship bands found on the right arm were similar to the ones worn by the missing man. Information of the missing person's general identity was compatible with autopsy findings. In presumptive identification of an unknown deceased, much information can be obtained by a detailed examination of the body, clothing and personal effects. However, there is a possibility that the unknown body is clothed with garments and personnel effects of another to mislead the investigators. Thus, it is not desirable to conclude positive identity based on these alone.

There are actually very few that can be considered as positive identification methods. These include dental records, finger print identification, finding medical implants, cranial suture pattern [5] and DNA analysis. [6] Availability of ante mortem records are a must to compare with in these methods, except in DNA analysis which can be concluded with comparison of samples of parents, siblings or children. In this victim the identity was confirmed as that of the missing young man using DNA profiling.

Once the positive identification is made, further investigations of the missing person's last movements can solve many unanswered questions. In this case, a second scene was revealed. Blood stain pattern analysis revealed evidence of a blood shedding event either before or after death.

Detailed autopsy examination did not reveal any definite ante mortem injuries. This is expected with peri-mortem infliction [7]. Furthermore, post-mortem mutilation and burns make it extremely hard to identify such injuries $[6,8]$. Burns were confirmed as postmortem due to the absence of soot in the airway and the absence of high carbon monoxide in blood [9]. Further, it could be confirmed that the body had been burnt after dismemberment due to involvement of burns in dismembered edges.

In the absence of definite ante mortem injuries to account for the death, the cause of death was concluded as unascertained, however an opinion was given that cut or chop injuries to the neck and abdomen as a cause of death cannot be excluded or concluded due to dismemberment and burning of the body.

\section{Conclusion}

Forensic investigation of dismembered human remains is a difficult task. Multidisciplinary crime scene investigations and meticulous autopsy is essential. At the end of the investigations, the identity was established and the initial scene was recovered. Intentional dismemberment and post-mortem mutilation with burns were confirmed. However, the cause of death was unascertained due to absence of definite ante mortem injuries. 


\section{References}

1. Hawley DA, Doedens DJ, McClain JL, Pless JE. Concealment of the body in drug deaths. J Forensic Sci. 1989 Mar;34(2):495-9

2. Kemkes-Grottenthaler $A$, The reliability of forensic osteology $-a$ case in point, case study, Forensic Sci. Int.2001; 117.. 65-72.

3. Pretty I, Sweet D. A look at forensic dentistry. Part 1 . The role of teeth in the determination of human identity, $\mathrm{Br}$. Dent.J. 2001; 190:359-366

4. Seleye-Fubara D, Etebu EN. Homicide In Port Harcourt Rivers State. Nig Jnl Orthopaedics \& Trauma 2003; Vol.2(2) 120-123

5. Rogers TL, Allard TT. Expert Testimony and Positive Identification of Human Remains Through Cranial Suture Patterns, Forensic Sci, Mar. 2004;Vol. 49, No. 2

6. Sheikh MI. Investigation of concealed homicide and establishment of positive identification. Journal of Clinical Pathology and Forensic Medicine 2011 Jan;Vol. 2(1) pp. $38-40$
7. Pr. Konstantinos Moraitis, Chara Spiliopoulou Identification and differential diagnosis of perimortem blunt force trauma in tubular long bones. Forensic Science, Medicine, and Pathology 2006; Volume 2. Issue 4: pp 221-229

8. Jovan Rajs, MajaLundstro“m,Magnus Broberg, Lars Lidberg, and Olle Lindquist, Criminal Mutilation of the Human Body in Sweden-A Thirty-Year Medico-Legal and Forensic Psychiatric Study; J Forensic Sci 1998;43(3):563-580

9. Levy, Angela D. Harcke, Howard T. Getz, John M. Mallak, Craig T. Multi-detector Computed Tomography Findings in Deaths with Severe Burns. American Journal of Forensic Medicine \& Pathology: June 2009; Volume 30 - Issue 2 - pp 137-141

\section{Contribution of authors}

Performing the autopsy- PAS

Opinion- PAS

Writing the manuscript -IDGK, PAS

Revising the manuscript- PAS, IDGK 